\title{
PERINATAL OUTCOME IN IDIOPATHIC OLIGOHYDRAMNIOS WITH AMNIOTIC FLUID INDEX < 5 CM COMPARED WITH NORMAL AMNIOTIC FLUID INDEX (5-25 CM) AT TERM
}

\author{
Sanjana Singh ${ }^{1}$, Ramkrishna Sahana², Subhendu Dasgupta ${ }^{3}$ \\ 1MS, Department of Obstetrics and Gynaecology, Bankura Sammilani Medical College and Hospital, Bankura, West Bengal, India. \\ ${ }^{2}$ Assistant Professor, Department of Obstetrics and Gynaecology, Bankura Sammilani Medical College and Hospital, Bankura, \\ West Bengal, India. \\ ${ }^{3}$ Professor and Ex-HOD, Department of Obstetrics and Gynaecology, Bankura Sammilani Medical College and Hospital, Bankura, \\ West Bengal, India.
}

\begin{abstract}
BACKGROUND
The importance of amniotic fluid volume as an indicator of foetal status is a relatively recent development. Oligohydramnios, AFI $<5$ $\mathrm{cm}$ has been circumstantially associated with a variety of ominous pregnancy outcome such as perinatal death, foetal distress in labour, poor infant condition at work. We wanted to assess the association of perinatal outcome in cases with oligohydramnios with $\mathrm{AFI}<5 \mathrm{~cm}$ diagnosed at term and compare it with perinatal outcome of controls (AFI $5-25 \mathrm{~cm}$ ).
\end{abstract}

\section{METHODS}

This prospective observational study was conducted in Bankura Sammilani Medical College and Hospital. 100 randomly selected cases with AFI $<5$ were analysed for perinatal outcome and compared with 100 controls (AFI 5 - 25). All relevant information was recorded and was appropriately analysed with SPSS 18.0 software. Antenatal women with gestational age of 37 completed weeks and above attending our Out Patient Department or labour rooms or emergency department were included in the study.

\section{RESULTS}

Women with oligohydramnios were more commonly associated with abnormal antepartum foetal heart rate (FHR), higher rate of caesarean section, Apgar score less than 7 or NICU admission.

\section{CONCLUSIONS}

This study concluded that oligohydramnios is associated with a high rate of pregnancy complications in the form of caesarean section and increased perinatal morbidity and mortality. Early intervention in the form of induction of labour, close intrapartum monitoring, artificial rupture of membranes in active phase of labour and grading of liquor and early decision-making regarding mode of delivery are the steps to be taken to prevent poor perinatal outcome. Immediately after birth, proper resuscitation by a paediatrician is mandatory.

\section{KEY WORDS}

Oligohydramnios, AFI, Apgar, NICU

HOW TO CITE THIS ARTICLE: Singh S, Sahana R, Dasgupta S. Perinatal outcome in idiopathic oligohydramnios with amniotic fluid index $<5 \mathrm{~cm}$ compared with normal amniotic fluid index (5-25 cm) at term. J. Evolution Med. Dent. Sci. 2019;8(29):2347-2350, DOI: $10.14260 /$ jemds/2019/514

\section{BACKGROUND}

The importance of amniotic fluid volume as an indicator of foetal status is a relatively recent development. It plays a major role in the development of foetus. Amniotic fluid allows proper growth and development of foetal long bones and musculoskeletal system. It has bacteriostatic and antiinflammatory properties.[1] There is gradual increase in volume with advancing gestation until approximately 31-33 weeks followed by a significant decrease towards and beyond the estimated date of confinement. Oligohydramnios is the condition of having too little amniotic fluid.

'Financial or Other Competing Interest': None.

Submission 19-05-2018, Peer Review 03-07-2019,

Acceptance 17-07-2019, Published 22-07-2019.

Corresponding Author:

Dr. Ramkrishna Sahana,

Subhankar Palli,

Post + Dist., Bankura,

West Bengal,

India.

E-mail: sahanadrramkrishna@gmail.com

DOI: $10.14260 /$ jemds/2019/514

\section{(c) $(\mathbf{P})$}

It is defined as amniotic fluid index less than 5 centimeters (or less than the 5th percentile) ${ }^{[2]}$ and has been circumstantially associated with variety of ominous pregnancy outcome, increasing maternal morbidity due to interventions and increased caesarean rate and adverse perinatal outcome due to foetal distress and foetal anoxia. Oligohydramnios can also be an idiopathic finding in a woman who had low risk pregnancies and no medical or foetal complication [3]. The common clinical features are smaller symphysio-fundal height, foetal mal-presentation, and undue prominence of the foetal parts and reduced amount of amniotic fluid.

Assessment of amniotic fluid volume by ultrasonography is more reliable. It is calculated as the sum of the deepest vertical dimension in each quadrant of the uterus. Complications may include cord compression, musculoskeletal abnormalities such as facial distortion and clubfoot, pulmonary hypoplasia and intrauterine growth restriction. Even a moderate reduction in AFV is associated with abnormal FHR, meconium stained liquor which often requires Caesarean Section and may result in perinatal morbidity and/or mortality.[4] Obstetricians have increasingly resorted to induction of labour or antepartum testing of 
foetal health in pregnancies complicated by decreased amniotic fluid volume. Due to wide spread application of sonogram derived estimates provoked unnecessary interventions.

The present study was carried out to assess the association of perinatal outcome in cases with oligohydramnios with $\mathrm{AFI}<5 \mathrm{~cm}$ diagnosed at term. The results are compared with perinatal outcome of controls (AFI $5-25 \mathrm{~cm}$ ) in a busy peripheral tertiary care hospital.

\section{METHODS}

This is a prospective observational study carried out in Department of Obstetrics and Gynaecology, Bankura Sammilani Medical College, Bankura, West Bengal, during the period from 1st March 2016 to 30th April 2017. The sample size is 200 (100 in each cases and control group).

Routine anomaly scan will be done at 18-20 weeks for all antenatal women to rule out anomalies followed by antenatal visits for low risk female 4 weekly till 28 weeks then 2 weekly till 36 weeks followed by weekly from 36 weeks to delivery. Fundal height, symphysio-fundal height, B.P., Proteinuria will be checked in every visit. OGTT with 75 gm glucose will be done at 24-28 weeks to rule out diabetes mellitus. Antenatal women with gestational age 37 completed weeks and above attending our Out Patient Department or Labour rooms or emergency department will be included in the present study.

\section{Inclusion Criteria}

1. Patients with accurately measured gestational age.

2. Gestational age 37 completed weeks to 42 weeks.

3. Singleton pregnancies with cephalic presentation.

4. Patients with AFI $<5 \mathrm{~cm}$ taken as study group and AFI 5$25 \mathrm{~cm}$ taken as control group.

\section{Exclusion Criteria}

1. Patients whose gestational age cannot be measured.

2. Pregnant women with gestational age less than 37 completed weeks.

3. Multiple pregnancies.

4. Patients complaining of premature rupture of membranes.

5. Patients with AFI $>25 \mathrm{~cm}$.

6. Pregnancy with any medical disorders like diabetes, chronic hypertension, new onset hypertension, cardiac diseases, renal diseases etc.

7. Foetal anomalies.

8. Patients with recurrent pregnancy loss or previous term IUD.

\section{Sampling Method and Ethical Consideration}

After taking written and informed consent and fulfilling the inclusion criteria and exclusion criteria, patients were included into the study. The study was carried out only after getting approval from the ethical committee.

\section{Study Design}

Prospective observational study.

\section{RESULTS}

\begin{tabular}{|c|c|c|c|c|}
\hline Variables & Cases & Controls & Total & p Value \\
\hline Age in years & $21.53 \pm 2.96$ & $21.23 \pm 2.92$ & $21.38 \pm 2.94$ & 0.472 \\
\hline BMI $\left(\mathrm{kg} / \mathrm{m}^{2}\right)$ & $20.81 \pm 0.80$ & $20.77 \pm 0.92$ & $20.79 \pm 0.86$ & 0.712 \\
\hline SBP $(\mathrm{mm} \mathrm{Hg})$ & $116.78 \pm 7.03$ & $116.64 \pm 7.03$ & $116.71 \pm 7.01$ & 0.888 \\
\hline DBP $(\mathrm{mm} \mathrm{Hg})$ & $77.76 \pm 5.09$ & $76.26 \pm 5.35$ & $77.01 \pm 5.26$ & $0.043^{*}$ \\
\hline Gestation age & $37.92 \pm 0.83$ & $37.94 \pm 0.93$ & $37.93 \pm 0.88$ & 0.898 \\
\hline
\end{tabular}

Table 1. Both Cases and Control are Comparable for Age, BMI and Blood Pressure, Gestation Age

\begin{tabular}{|c|c|c|c|}
\hline Booked/Un booked & Cases & Controls & Total \\
\hline Booked & $63(63 \%)$ & $84(84 \%)$ & $147(73.5 \%)$ \\
\hline Unbooked & $37(37 \%)$ & $16(16 \%)$ & $53(26.5 \%)$ \\
\hline Total & $100(100 \%)$ & $100(100 \%)$ & $200(100 \%)$ \\
\hline \multicolumn{4}{|c|}{ Table 2. Comparison of Booking Status Between Cases and Controls } \\
\hline $\begin{array}{l}\text { Statistical analysis was done using chi-square test and p- value was found to be } 0.001 \\
\text { which is statistically significant. Table 2: shows that out of 100 patients in cases 37\% } \\
\text { were unbooked and 16\% were uncooked in control. Comparing both the groups low } \\
\text { AFI is more common in unbooked cases compared to booked cases indicating that } \\
\text { proper antenatal care with emphasis on amount of liquor clinically an early } \\
\text { admission as per requirement reduces the number of cases with oligohydramnios. }\end{array}$ \\
\hline
\end{tabular}

\begin{tabular}{|c|c|c|c|}
\hline Parity & Cases & Controls & Total \\
\hline 0 & $79(79 \%)$ & $77(77 \%)$ & $156(78 \%)$ \\
\hline 1 & $17(17 \%)$ & $20(20 \%)$ & $37(18.5 \%)$ \\
\hline 2 & $3(3 \%)$ & $3(3 \%)$ & $6(3 \%)$ \\
\hline 3 & $1(1 \%)$ & $0(0 \%)$ & $1(0.5 \%)$ \\
\hline Total & $\mathbf{1 0 0}(\mathbf{1 0 0} \%)$ & $\mathbf{1 0 0}(\mathbf{1 0 0} \%)$ & $\mathbf{2 0 0}(\mathbf{1 0 0} \%)$ \\
\hline \multicolumn{2}{|l}{ Table 3. Comparison of Parity Between Cases and Controls } \\
\end{tabular}

Statistical analysis done using Fisher Exact test with the $P$ value 0.910 and was statistically not significant. The above table shows that there is no significan difference found in the parity of patients among the cases and control.

\begin{tabular}{|c|c|c|c|}
\hline Bishop Score Unfavorable & Cases & Controls & Total \\
\hline Unfavorable $(<=6)$ & $41(41 \%)$ & $13(13 \%)$ & $54(27 \%)$ \\
\hline Favorable $(>6)$ & $59(59 \%)$ & $87(87 \%)$ & $146(73 \%)$ \\
\hline Total & $\mathbf{1 0 0}(\mathbf{1 0 0} \%)$ & $\mathbf{1 0 0 ( 1 0 0 \% )}$ & $\mathbf{2 0 0 ( 1 0 0 \% )}$ \\
\hline
\end{tabular}

Table 4. Comparison Between Bishop Score Unfavorable Distribution in Cases and Controls

Statistical analysis done using Chi-Square test with $\mathrm{P}$ value $<0.001$ and was statistically significant.

\begin{tabular}{|c|c|c|c|}
\hline Labour & Cases & Controls & Total \\
\hline Spontaneous & $54(54 \%)$ & $86(86 \%)$ & $140(70 \%)$ \\
\hline Induced & $46(46 \%)$ & $14(14 \%)$ & $60(30 \%)$ \\
\hline Total & $100(100 \%)$ & $100(100 \%)$ & $200(100 \%)$ \\
\hline \multicolumn{4}{|c|}{$\begin{array}{c}\text { Table 5. Comparison Between Spontaneous/Induced Labour } \\
\text { Distribution in Cases and Controls }\end{array}$} \\
\hline
\end{tabular}

\begin{tabular}{|c|c|c|c|}
\hline Colour Liquor & Cases & Controls & Total \\
\hline Clear & $56(56 \%)$ & $82(82 \%)$ & $138(69 \%)$ \\
\hline Meconium & $44(44 \%)$ & $18(18 \%)$ & $62(31 \%)$ \\
\hline Total & $100(100 \%)$ & $100(100 \%)$ & $200(100 \%)$ \\
\hline
\end{tabular}

Table 6. Comparison of Colour of Liquor Between Cases and Controls

$\mathrm{P}<0.001^{* *}$, significant, Chi-Square test. The incidence of meconium stained liquor in cases was $44 \%$ when compared to control group $18 \%$.

\begin{tabular}{|c|c|c|c|}
\hline CTG & Cases & Controls & Total \\
\hline Reactive & $50(50 \%)$ & $89(89 \%)$ & $139(69.5 \%)$ \\
\hline Non-Reactive & $50(50 \%)$ & $11(11 \%)$ & $61(30.5 \%)$ \\
\hline Total & $100(100 \%)$ & $100(100 \%)$ & $200(100 \%)$ \\
\hline \multicolumn{4}{|c|}{$\begin{array}{c}\text { Table 7. Comparison of Foetal Heart Rate Abnormality in CTG } \\
\text { Distribution Between Cases and Controls }\end{array}$} \\
\hline
\end{tabular}

\begin{tabular}{|c|c|c|c|}
\hline Mode of Delivery & Cases & Controls & Total \\
\hline Vaginal & $31(31 \%)$ & $70(70 \%)$ & $101(50.5 \%)$ \\
\hline LSCS & $61(61 \%)$ & $28(28 \%)$ & $89(44.5 \%)$ \\
\hline Instrumental & $8(8 \%)$ & $2(2 \%)$ & $10(5 \%)$ \\
\hline Total & $\mathbf{1 0 0 ( 1 0 0 \% )}$ & $\mathbf{1 0 0}(\mathbf{1 0 0} \%)$ & $\mathbf{2 0 0 ( 1 0 0 \% )}$ \\
\hline
\end{tabular}

Table 8. Comparison of Mode of Delivery Distribution in Cases and Controls

$\mathrm{P}=0.002$, significant, Chi-Square test. The above analysis shows that in cases the incidence of caesarean section rate $(61 \%)$ and instrumental delivery $(8 \%)$ is high when compared to control group. 


\begin{tabular}{|c|c|c|c|}
\hline Indication & Cases & Controls & Total \\
\hline Foetal distress & $52(75.4 \%)$ & $11(36.7 \%)$ & $63(63.6 \%)$ \\
\hline others & $17(24.6 \%)$ & $19(63.3 \%)$ & $36(36.4 \%)$ \\
\hline Total & $\mathbf{6 9 ( 1 0 0 \% )}$ & $\mathbf{3 0 ( 1 0 0 \% )}$ & $\mathbf{9 9 ( 1 0 0 \% )}$ \\
\hline \multicolumn{4}{|c|}{ Table 9. Comparison of Indication of Caesarean Section in Cases and } \\
Controls
\end{tabular}

On analysing the indications for caesarean section foetal distress was found to b dominant indication in cases $(75.4 \%)$ when compared to control $(36.7 \%)$. This difference was found to be significant by chi-square test ( $\mathrm{p}<0.05 \%)$.

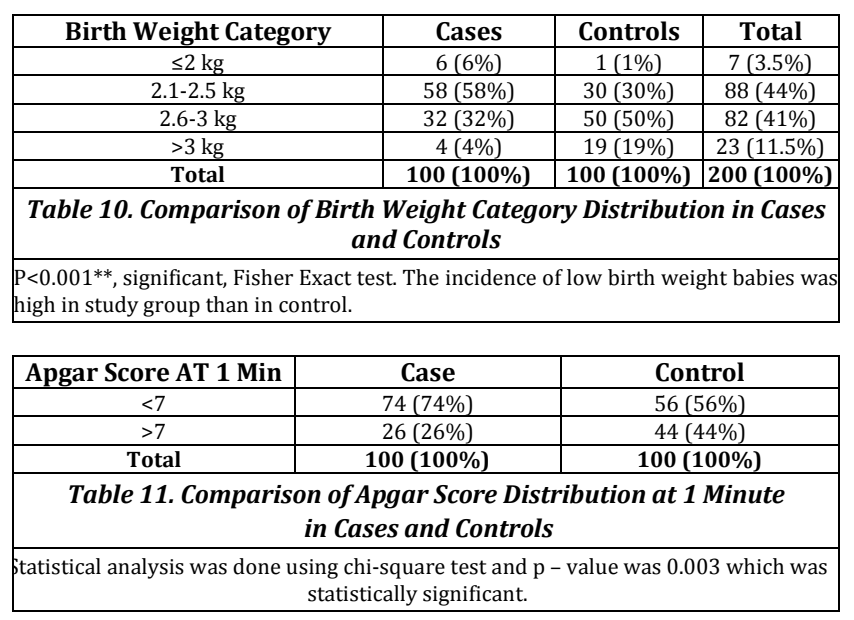

\begin{tabular}{|c|c|c|}
\hline Apgar Score at 5 Min & Case & Control \\
\hline$<7$ & $25(25 \%)$ & $7(7 \%)$ \\
\hline$>7$ & $75(75 \%)$ & $93(93 \%)$ \\
\hline Total & $\mathbf{1 0 0}(100 \%)$ & $\mathbf{1 0 0}(100 \%)$ \\
\hline \multicolumn{2}{|c|}{ Table 12. Comparison of Apgar Score Distribution at 5 Minute } \\
in Cases and Controls
\end{tabular}

Statistical analysis was done using chi-square test and $p$ - value was 0.0002 which is statistically significant. The APGAR scores at 5 minutes were compared between the study and control groups. $25 \%$ of the cases in study group had APGAR less than 7, compared to $7 \%$ of cases in control group.

\begin{tabular}{|c|c|c|c|}
\hline SNCU & Cases & Controls & Total \\
\hline No Admission & $63(63 \%)$ & $91(91 \%)$ & $154(77 \%)$ \\
\hline Admission & $37(37 \%)$ & $9(9 \%)$ & $46(23 \%)$ \\
\hline Total & $100(100 \%)$ & $100(100 \%)$ & $200(100 \%)$ \\
\hline \multicolumn{4}{|c|}{ Table 13. Comparison of SNCU Admission in Cases and Controls } \\
\hline \multicolumn{4}{|c|}{$\begin{array}{l}\text { Statistical analysis was done using chi-square test and } p-\text { value was }<0.001 \text {, and } \\
\text { hence statistically significant. The incidence of NICU admission in study group }(37 \%) \\
\text { when compared to } 9 \% \text { in control group. There is a clear association between } \\
\text { oligohydramnios and increased incidence of NICU admissions. }\end{array}$} \\
\hline Perinatal Death & Cases & Controls & Total \\
\hline No & $98(98 \%)$ & $100(100 \%)$ & 198 (99\%) \\
\hline Yes & $2(2 \%)$ & $0(0 \%)$ & $2(1 \%)$ \\
\hline Total & $100(100 \%)$ & $100(100 \%)$ & $200(100 \%)$ \\
\hline \multicolumn{4}{|c|}{ Table 14. Comparison of Perinatal Death in Cases and Controls } \\
\hline 497, Not signi & isher Exac & & \\
\hline
\end{tabular}

\section{Statistical Analysis}

Descriptive and inferential statistical analysis has been carried out in the present study. Results on continuous measurements are presented on Mean \pm SD (Min-Max) and results on categorical measurements are presented in Number (\%). Significance is assessed at $5 \%$ level of significance. Student $t$ test (two tailed, independent) has been used to find the significance of study parameters on continuous scale between two groups (Inter group analysis) on metric parameters. Chi-square/ Fisher Exact test has been used to find the significance of study parameters on categorical scale between two or more groups, Nonparametric setting for Qualitative data analysis. Fisher exact test used when cell samples are very small. $\mathrm{p}$-value $<0.05$ was considered statistically significant.

\section{DISCUSSION}

In the present study the mean age of the cases in the oligohydramnios group was $21.53 \pm 2.96$ years and the mean age of the patients in the control group was $21.23 \pm 2.92$ years. Our study was consistent with the study by Madhavi et al,[5] there was no significant difference found in the age group of patients among the study and control.

In our study $37 \%$ of the cases were unbooked compared to $16 \%$ of controls and $73.5 \%$ of the overall population was booked while $23.5 \%$ was unbooked. In the present study Pvalue was statistically significant. Similar results were found in the study by Madhavi et al in which $32 \%$ of patients were unbooked in study group and $20 \%$ patients were unbooked in control group.

In our study, $78 \%$ of the patients were primigravida. Similarly Jagatia et al[6] reported that the incidence of oligohydramnios was more in primipara $(52.0 \%)$ which was compatible with the study of Jandial et al[7] who showed that the incidence of oligohydramnios was $60.0 \%$ in primigravida.

In our study $46 \%$ of the cases were induced and $14 \%$ of patients in control group were induced. In a study by Madhavi et al the induction of labour was significantly high in study group (48\%). In a study by Kahkhaie et al[8] there was significant statistically difference in induction of labour so that the induction of labour in oligohydramnios was 3.22 times greater than the control group.

In our study the incidence of meconium stained liquor was $44 \%$ in cases and $18 \%$ in control. In a study by Madhavi et al[5], the incidence of meconium stained liquor in the study group was $36 \%$ when compared to control group which was $14 \%$,with $P$ value $<0.03$. In a study by Chaudhari et al [9] 48 patients out of 156 patients with oligohydramnios had meconium staining of amniotic fluid which was $30.76 \%$. There was a significant relation between the meconium staining of amniotic fluid and oligohydramnios.

In our study the incidence of non-reactive CTG was more in cases $(50 \%)$ than in control (11\%). In a study by Nazlima et al[10] showed that out of 78 patients with oligohydramnios, $33 \%$ had normal CTG and 66\% had abnormal CTG on admission. In a study by Patel et al[11] non- reactive CTG was significantly higher in women with isolated oligohydramnios(65\%).

In our study, the mode of delivery was significantly influenced by the presence of oligohydramnios. Caesarean deliveries were high $(61 \%)$ in patients with oligohydramnios and most of them were due to non-reactive CTG and foetal distress. whereas the rate of caesarean deliveries was $28 \%$ in patients with AFI $>=5$. Our result was similar to the result of Madhavi et al where the percentage of caesarean section was $58 \%$ in cases and $30 \%$ in control.

In our study, majority (58\%) of the babies in oligohydramnios group had birth weight between $2.1-2.5$ $\mathrm{kg}$. $32 \%$ had birth weight between $2.5-3.0 \mathrm{~kg}$ while $06 \%$ weighed below $2.0 \mathrm{~kg}$. Only $4 \%$ had birth weight above $3.0 \mathrm{~kg}$. In a study by Madhavi et al The incidence of low birth weight babies was as high as $56 \%$. The rate of low birth weight was high 79.4\% in studies by Youssef et al.[12]

In the present study, the association of oligohydramnios with low Apgar score was strong. In our study, $74 \%$ of babies belonging to the oligohydramnios group had Apgar score $<7$ at $1 \mathrm{~min}$. 25\% of the babies belonging to cases had Apgar score $<7$ at 5 min., The study by Nazlima et al showed $21 \%$ of 
the babies to have Apgar score $<7$ at 5 minutes in the oligohydramnios group.

In our study, $37 \%$ of the babies born of cases needed admission in SNCU in comparison to control in which only $9 \%$ babies needed admission which was similar to the result of Madhavi et al where the incidence of NICU admission in study group (34\%) when compared to $8 \%$ in control group.

In our study $2 \%$ of the babies in oligohydramnios group died. None of the babies died in the control group. In a study by Nazlima et al $2.4 \%$ perinatal deaths were present. Choudhary et al reported 2 perinatal deaths (1.3\%).

\section{CONCLUSIONS}

- No significant correlation was seen between oligohydramnios and maternal age and also between oligohydramnios and gestational age.

- Incidence of operative deliveries (instrumental vaginal delivery and caesarean section) is significantly increased in patients with isolated oligohydramnios.

- The risks of meconium staining of liquor, intrapartum foetal distress, and perinatal mortality are higher in patients with $\mathrm{AFI}<5 \mathrm{~cm}$.

- The goal of antepartum foetal surveillance is to identify the foetus at risk. Hence the estimation of amniotic fluid index assists the obstetrician in risk assessment. Of the various semi quantitative methods described, four quadrant technique for AFI provides a most convenient and reproducible method of evaluating amniotic fluid volume.

- Early intervention in the form of induction of labour, close intrapartum monitoring, artificial rupture of membranes in active phase of labour and grading of liquor and early decision-making regarding mode of delivery are the steps to be taken to prevent poor perinatal outcome. Immediately after birth, proper resuscitation by a paediatrician is mandatory.

\section{REFERENCES}

[1] Munn MB. Management of Oligohydramnios in pregnancy. Obstet Gynecol Clin North Am 2011;38(2):387-95.
[2] Phelan JP, Smith CV, Broussard P, et al. Amniotic fluid volume assessment with the four-quadrant technique at 36-42 weeks' gestation. J Reprod Med 1987;32(7):540-2.

[3] Leeman L, Almond D. Isolated oligohydramnios at term: is induction indicated? J Fam Pract 2005;54(1):25-32.

[4] Gupta R, Porwal SK, Swarnkar M, et al. the role of intravenous amino acid infusion in Oligohydramnios. Int J Pharm Sci Res 2012;3(10):3971-4. www.ijpsr.com

[5] Madhavi K, Rao PC. Clinical study of Oligohydramnios, mode of delivery and perinatal outcome. IOSR J Dental \& Medical Sciences (IOSR-JDMS) 2015;14(4)Ver. X:0611.

[6] Jagatia K, Singh N, Patel S. Maternal and foetal outcome in Oligohydramnios: a study of 100 cases: International Journal of Medical Science and Public Health 2013;2(3):724-7.

[7] Jandial C, Gupta S, Sharma S, et al. Perinatal outcome after antepartum diagnosis of Oligohydramnios at or beyond 34 weeks of gestation. JK Science 2007;9(4):213-14.

[8] Kahkhaie KR, Keikha F, Keikhaie KR, et al. Perinatal outcome after diagnosis of Oligohydramnious at term. Iran Red Crescent Med J 2014;16(5):e11772.

[9] Chaudhari KR, Chaudhari KR, Desai OM. Perinatal outcome associated with Oligohydramnios in third trimester. Int J Reprod Contracept Obstet Gynecol 2017;6(1):72-5.

[10] Nazlima N, Fatima B. Oligohydramnios at third trimester and perinatal outcome. Bangladesh Journal of Medical Science 2012;11(1):33-6.

[11] Patel PK, Pitre DS, Gupta H. Pregnancy outcome in isolated Oligohydramnios at term. Ntl J of Community Med 2015;6(2):84-8.

[12] Youssef AA, Abdulla SD, Sayed EH, et al. Superiority of amniotic fluid index over amniotic fluid pocket measurement for predicting bad foetal outcome. Southern Medical Journal 1993;86(4):426-9. 